\title{
Apoptosis- and differentiation-inducing activities of jacaric acid, a conjugated linolenic acid isomer, on human eosinophilic leukemia EoL-1 cells
}

\author{
WAI-NAM LIU and KWOK-NAM LEUNG \\ Biochemistry Programme, School of Life Sciences, \\ The Chinese University of Hong Kong, Shatin, Hong Kong, SAR, P.R. China
}

Received May 21, 2014; Accepted July 14, 2014

DOI: $10.3892 /$ or.2014.3446

\begin{abstract}
Conjugated linolenic acids (CLNAs) are a group of naturally occurring positional and geometrical isomers of the C18 polyunsaturated essential fatty acid, linolenic acid (LNA), with three conjugated double bonds (C18:3). Although previous research has demonstrated the growth-inhibitory effects of CLNA on a wide variety of cancer cell lines in vitro, their action mechanisms and therapeutic potential on human myeloid leukemia cells remain poorly understood. In the present study, we found that jacaric acid $(8 Z, 10 E, 12 Z$-octadecatrienoic acid), a CLNA isomer which is present in jacaranda seed oil, inhibited the in vitro growth of human eosinophilic leukemia EoL-1 cells in a time- and concentration-dependent manner. Mechanistic studies showed that jacaric acid triggered cell cycle arrest of EoL-1 cells at the $G_{0} / G_{1}$ phase and induced apoptosis of the EoL-1 cells, as measured by the Cell Death Detection ELISA $^{\text {PLUS }}$ kit, Annexin V assay and JC-1 dye staining. Notably, the jacaric acid-treated EoL-1 cells also underwent differentiation as revealed by morphological and phenotypic analysis. Collectively, our results demonstrated the capability of jacaric acid to inhibit the growth of EoL-1 cells in vitro through triggering cell cycle arrest and by inducing apoptosis and differentiation of the leukemia cells. Therefore, jacaric acid might be developed as a potential candidate for the treatment of certain forms of myeloid leukemia with minimal toxicity and few side effects.
\end{abstract}

\section{Introduction}

Leukemia is a cancer of the blood or bone marrow and is the result of uncoupling or imbalance of the proliferation and

Correspondence to: Professor Kwok-Nam Leung, Biochemistry Programme, School of Life Sciences, The Chinese University of Hong Kong, Shatin, Hong Kong, SAR, P.R. China

E-mail: knleung@cuhk.edu.hk

Key words: apoptosis, cell cycle arrest, differentiation, EoL-1 cells, jacaric acid differentiation of hematopoietic stem cells (HSCs) (1). The malignant cells continue to proliferate with the loss of differentiation capability, and abnormalities in the development of HSCs at any stage may result in leukemia (2). Current treatment strategies for leukemia include cytotoxic drug therapy, radiotherapy and bone marrow transplantation. Nevertheless, they are usually accompanied by numerous adverse side effects. In the last two decades, remarkable progress has been made in the treatment of leukemia, yet problems such as cancer cell heterogeneity, chromosomal instability, lack of selective action of anti-neoplastic agents and development of multidrug resistance, still remain to be solved (3). Therefore, there is a pressing need to develop new compounds with high therapeutic efficacy on leukemia cells but with minimal toxicity on normal cells, especially those derived from natural sources.

Conjugated fatty acids (CFAs) refer to the positional and geometric isomers of polyunsaturated fatty acids (PUFAs) in which two carbon-carbon double bonds are separated by one carbon-carbon single bond $(-\mathrm{C}=\mathrm{C}-\mathrm{C}=\mathrm{C}-)$ (4). Naturally occurring CFAs can be isolated from meat and dairy products of ruminant animals (5), plant seed oils (6) and seaweeds (conjugated tetraenoic acid, conjugated eicosapentaenoic acid and conjugated docosahexaenoic acid) (7). Among all CFAs, conjugated linoleic acid (CLA) has been the most extensively studied in relation to its occurrence, metabolism and physiological effects (8). Nevertheless, the occurrence of CLA in natural food is found to be $<1 \%$, while conjugated linolenic acid (CLNA) is present at a higher concentration in natural food $(30-70 \%)$, especially in some plant seed oils $(6,9)$. Previous research has demonstrated the various beneficial effects of CLNA on human health, including anti-obesity, hypolipidemic, anti-inflammatory, immunomodulatory and cancer chemopreventive activities (9-11). A previous study showed that conjugated trienoic fatty acids produced by alkali isomerization of $\alpha$-linolenic acid at concentrations above $25 \mu \mathrm{M}$ displayed potent antitumor effects on a wide range of human cancer cell lines in vitro, including hepatoma (HepG2), lung adenocarcinoma (A549), breast adenocarcinoma (MCF-7), stomach tubular adenocarcinoma (MKN-7) and colon carcinoma (DLD-1) (12). Interestingly, it has been shown that CLNA exhibits a stronger antitumor effect than CLA on various types of human cancer cells $(12,13)$. In another study, it was found 
that $\alpha$-eleostearic acid $(9 Z, 11 E, 13 E$-octadecatrienoic acid), an isomer of CLNA, induced DNA fragmentation, increased caspase activity and expression of caspase mRNA in human colon cancer DLD-1 cells (13). Moreover, Grossmann et al (14) showed that the growth-inhibitory and apoptosis-inducing effects of $\alpha$-eleostearic acid on human breast cancer cells might be mediated by an oxidation-dependent mechanism. These earlier results suggest that $\alpha$-eleostearic acid is a CLNA isomer that might have potential in the treatment of breast and colon cancers. Yet, the antitumor effects of CLNA isomers on various types of human myeloid leukemia cells and their action mechanisms remain poorly understood, both in vitro and in vivo.

In the present study, we found that jacaric acid $(8 \mathrm{Z}, 10 E, 12 Z$ -octadecatrienoic acid; Fig. 1) is the most potent CLNA isomer that can significantly inhibit the growth of human eosinophilic leukemia EoL-1 cells in vitro. Mechanistic studies indicated that jacaric acid exerts its anti-leukemic action through triggering of cell cycle arrest, and by inducing the apoptosis and differentiation of leukemia cells.

\section{Materials and methods}

Chemicals and reagents. CLNAs used in the study, which include $\alpha$-eleostearic acid, $\beta$-eleostearic acid, $\beta$-calendic and jacaric acid, with an estimated purity $>97 \%$, were purchased from Larodan Fine Chemicals AB, Sweden. The stock solution $(0.2 \mathrm{M})$ was prepared by dissolving the powder in sterile, cell culture-tested ethanol (Sigma-Aldrich Co., USA). All other chemicals were purchased from Sigma-Aldrich unless otherwise stated.

Culture of the tumor cell line. The human eosinophilic leukemia EoL-1 cell line obtained from the Riken Cell Bank (Tsukuba Science City, Japan) was originally established from the peripheral blood of a 33-year-old male with eosinophilic leukemia (15). The cells were maintained in RPMI-1640 medium (Gibco, USA) supplemented with 10\% fetal bovine serum (FBS; Gibco) and $1 \%$ antibiotics (100 U/ $\mathrm{ml}$ penicillin $\mathrm{G}, 100 \mu \mathrm{g} / \mathrm{ml}$ streptomycin sulfate and $0.25 \mu \mathrm{g} /$ $\mathrm{ml}$ amphotericin B in $0.85 \%$ saline) in 5\% humidified air at $37^{\circ} \mathrm{C}$.

In vitro assays for the anti-proliferative activity. Cell proliferation was measured using both the colorimetric MTT assay and fluorometric cell proliferation assay. Briefly, EoL-1 cells $\left(1 \times 10^{5} / \mathrm{ml}\right)$ seeded in $96-$ well microtiter plates were incubated at $37^{\circ} \mathrm{C}$ with different concentrations of jacaric acid for various periods of time. The anti-proliferative response was measured by a standard MTT colorimetric assay (16) and recorded by a Benchmark microplate reader (Bio-Rad Laboratories, USA). The result was also confirmed by using the CyQuant ${ }^{\circledR}$ NF Cell Proliferation Assay kit (Molecular Probes; Invitrogen Corp., USA) (17) and recorded using a fluorescence plate reader (Tecan Polarion, USA).

Analysis of cell cycle profile. EoL-1 cells $\left(1 \times 10^{5} / \mathrm{ml}\right)$ were synchronized with $0.5 \%$ heat-inactivated FBS (HI-FBS) overnight and incubated at $37^{\circ} \mathrm{C}$ with different concentrations of jacaric acid. Afterwards, the cells were stained by propidium iodide (PI) (Sigma-Aldrich), and the cell cycle profile was analyzed by flow cytometry (FACSCanto ${ }^{\mathrm{TM}}$ flow cytometer; BD BioSciences, USA) using the software ModFit LT V3.0 (Verity Software House).

Measurement of DNA fragmentation by Cell Death Detection ELISA ${ }^{\text {PLUS }}$ kit. The measurement was performed according to the manufacturer's instructions in the Cell Death Detection ELISA $^{\text {PLUS }}$ kit (Roche Applied Science, USA). Briefly, EoL-1 cells $\left(1 \times 10^{5} / \mathrm{ml}\right)$ were incubated with different concentrations of jacaric acid at $37^{\circ} \mathrm{C}$ for various periods of time. The supernatant was transferred to the well of a streptavidin-coated 96-well microtiter plate, and the absorbance was measured at $405 \mathrm{~nm}$. The degree of apoptosis was expressed as the enrichment factor, which was calculated as follows: Enrichment factor $=$ DNA fragments in treated sample/DNA fragments in the control.

Analysis of Annexin V-GFP/PI dual staining profile. Induction of apoptosis can also be measured using Annexin V-GFP/PI dual staining method. Briefly, EoL-1 cells $\left(1 \times 10^{5} / \mathrm{ml}\right)$ were incubated with different concentrations of jacaric acid at $37^{\circ} \mathrm{C}$ for $24 \mathrm{~h}$. The cells were then resuspended in Annexin V binding buffer (BD Biosciences) supplemented with Annexin V-GFP fusion protein and PI. The samples were incubated for $30 \mathrm{~min}$ at room temperature and were analyzed for PerCP-Cy5.5 with an emission wavelength of $695 \mathrm{~nm}$ versus FITC fluorescence with an emission wavelength of $525 \mathrm{~nm}$ by the FACSCanto flow cytometer. The percentages of cells in the four quadrants were calculated by WinMDI (version 2.9) software.

Determination of mitochondrial membrane potential by $J C-1$ staining. EoL-1 cells $\left(1 \times 10^{5} / \mathrm{ml}\right)$ were incubated with different concentrations of jacaric acid at $37^{\circ} \mathrm{C}$ for $24 \mathrm{~h}$. Afterwards, the cells were resuspended in PBS supplemented with JC-1 dye (Molecular Probes; Invitrogen). The samples were incubated for $30 \mathrm{~min}$ at $37^{\circ} \mathrm{C}$ and then analyzed for red fluorescence (FL-2) with an emission wavelength of $575 \mathrm{~nm}$ vs. green fluorescence (FL-1) with an emission wavelength of $525 \mathrm{~nm}$ by the FACSCanto flow cytometer. The percentages of cells with membrane depolarization were calculated by WinMDI (version 2.9) software.

Western blot analysis. Protein expression was determined by western blot technique using a panel of specific antibodies. EoL-1 cells $\left(1 \times 10^{5} / \mathrm{ml}\right)$ were incubated with different concentrations of jacaric acid at $37^{\circ} \mathrm{C}$ for $72 \mathrm{~h}$. Cell pellets were collected and total proteins were extracted using cell lysis buffer. The protein concentration was measured using Bradford reagent (Sigma-Aldrich), and the protein samples were resolved on $12 \%$ polyacrylamide gels and transferred to PVDF membranes. The membranes were first incubated with the following primary antibodies: mouse anti-human Bax, Bcl-2, caspase-3, CDK2 and rabbit anti-human cyclin E antibodies (all from Santa Cruz Biotechnology, USA), rabbit anti-human pp53 antibody (Cell Signaling) and mouse anti-human $\beta$-actin antibody (Sigma-Aldrich), followed by incubation with HRP-conjugated secondary antibodies (GE Healthcare Ltd., UK) and finally developed with ECL reagent (Santa Cruz). 
<smiles>CCCCC/C=C\C=C/C=C\CCCCCCC(=O)O</smiles>

Figure 1. Chemical structure of jacaric acid.

Cell morphological study. The procedures were similar as previously described with slight modifications (18). In brief, EoL-1 cells $\left(1 \times 10^{5} / \mathrm{ml}\right)$ were incubated with different concentrations of jacaric acid at $37^{\circ} \mathrm{C}$ for 9 days. At day 4 and day 7 of the treatment, treated cells were washed with plain medium, and the cells $\left(1 \times 10^{5} / \mathrm{ml}\right)$ were further incubated with fresh medium supplemented with jacaric acid. Cell morphology was then determined by the preparation of cytospin smears. The EoL-1 cells $\left(5 \times 10^{4}\right)$ were fixed onto a microscopic slide by cytocentrifugation at $500 \mathrm{rpm}$ for $5 \mathrm{~min}$ using the Shandon Cytospin 3 centrifuge (Shandon Scientific Ltd., UK). The cells were air-dried and then stained with Hemacolor staining solutions (Diagnostica Merck, USA) for $15 \mathrm{sec}$ and destained under de-ionized water. Finally, the air-dried cells on the slides were mounted with neutral mounting medium, Canada balsam (Sigma-Aldrich), and morphology was examined under a light microscope.

Detection of eosinophil peroxidase (EPO) and major basic protein $(M B P)$ expression by flow cytometry. The procedures of Lung et al (18) were followed with slight modifications. EoL-1 cells $\left(1 \times 10^{5} / \mathrm{ml}\right)$ were incubated with different concentrations of jacaric acid at $37^{\circ} \mathrm{C}$ for 9 days. At day 4 and day 7 of the treatment, treated cells were washed with plain RPMI medium, and the cells $\left(1 \times 10^{5} / \mathrm{ml}\right)$ were further incubated with fresh medium supplemented with jacaric acid. The cells were harvested and fixed with $100 \%$ ice-cold methanol for $10 \mathrm{~min}$ at $4^{\circ} \mathrm{C}$ and washed once with PBS. Afterwards, the cells were incubated with normal mouse IgG (1 mg/ml; Sigma-Aldrich) for $30 \mathrm{~min}$ before staining with mouse anti-human EPO or mouse anti-human MBP monoclonal antibodies $(0.5 \mathrm{mg} / \mathrm{ml}$; Pharmingen Inc., USA) for $2 \mathrm{~h}$. Lastly, the cells were incubated with FITC-labeled goat anti-mouse IgG $(0.5 \mathrm{mg} / \mathrm{ml}$; SigmaAldrich) for $1 \mathrm{~h}$. The stained cells were analyzed for FITC fluorescence with an emission wavelength of $525 \mathrm{~nm}$ by the FACSCanto flow cytometer.

Statistical analysis. Each experiment was repeated at least three times and only the results of the most representative experiments are shown. The data are expressed as the arithmetic mean \pm standard error (SE). One-way analysis of variance (ANOVA) or unpaired Student's t-test was used for statistical analysis and the differences were considered as statistically significant at $\mathrm{P}<0.05$.

\section{Results}

Anti-proliferative effect of conjugated linolenic acid (CLNA) isomers on human eosinophilic leukemia EoL-1 cells. To
A

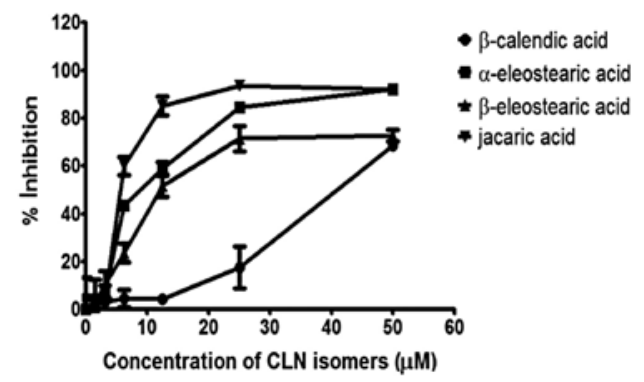

B

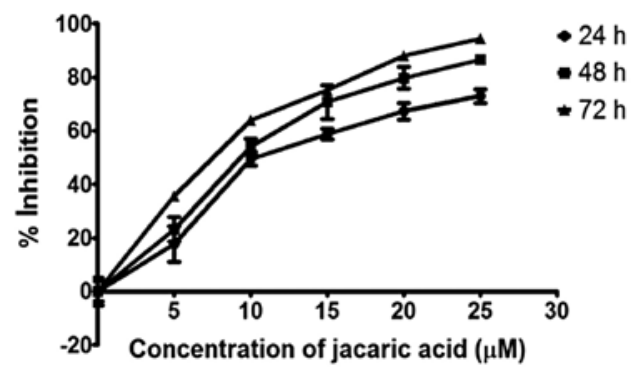

C

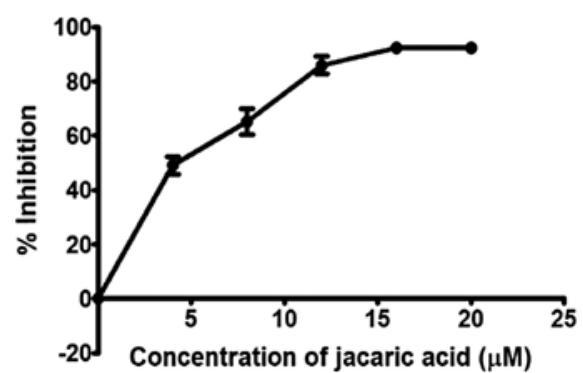

Figure 2. Anti-proliferative effect of conjugated linolenic acid (CLNA) isomers on the human eosinophilic leukemia EoL-1 cells. (A) EoL-1 cells were incubated with different concentrations of CLNA isomers at $37^{\circ} \mathrm{C}$ for $48 \mathrm{~h}$ (B and C) EoL-1 cells were incubated with jacaric acid at $37^{\circ} \mathrm{C}$ for different periods of time. Cells treated with $0.01 \%$ ethanol acted as the control. The cell growth was determined by MTT reduction assay (A and B), and using the CyQuant ${ }^{\circledR}$ NF Cell Proliferation Assay kit (C). The results are expressed as the mean percentage of inhibition of cell proliferation \pm SE of quadruplicate cultures.

determine the anti-proliferative effect of CLNA isomers on the EoL-1 cells, the MTT reduction assay was performed. As shown in Fig. 2A, all four CLNA isomers were found to exhibit an inhibitory effect on the proliferation of EoL-1 cells in a concentration-dependent manner. In contrast, the solvent control (up to $0.1 \% \mathrm{v} / \mathrm{v}$ ethanol) did not exert any significant inhibitory effect on EoL-1 cells ( $<5 \%$ inhibition, data not shown). Jacaric acid was found to be the most potent isomer among all the CLNA isomers tested and therefore it was chosen as the specific target for further investigation in the present study. Fig. 2B shows that jacaric acid inhibited the growth of EoL-1 cells in a time- and concentration-dependent manner, and the estimated $50 \%$ inhibitory concentration $\left(\mathrm{IC}_{50}\right)$ after a 48 -h treatment was found to be $5.33 \pm 0.86 \mu \mathrm{M}$. The growthinhibitory effect of jacaric acid on EoL-1 cells was confirmed by the CyQuant ${ }^{\circledR}$ NF Cell Proliferation Assay kit (Fig. 2C). 
A

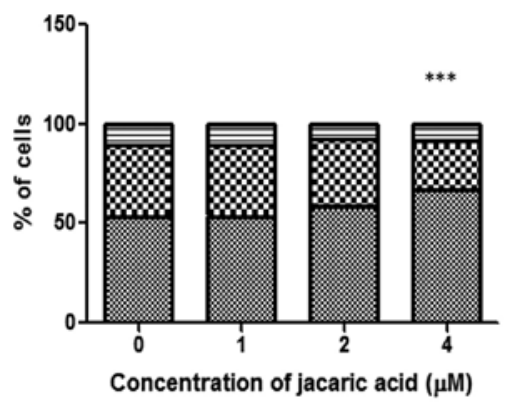

$\mathrm{C}$

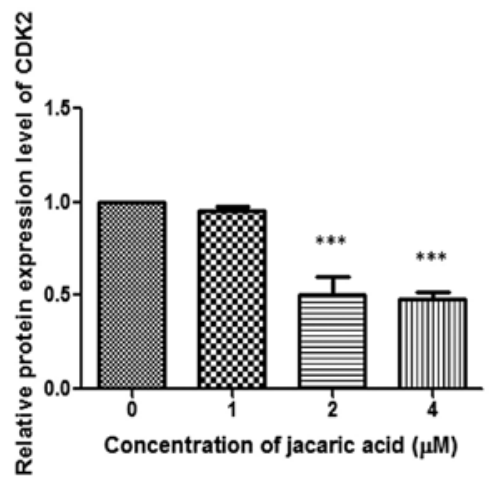

$\mathrm{B}$

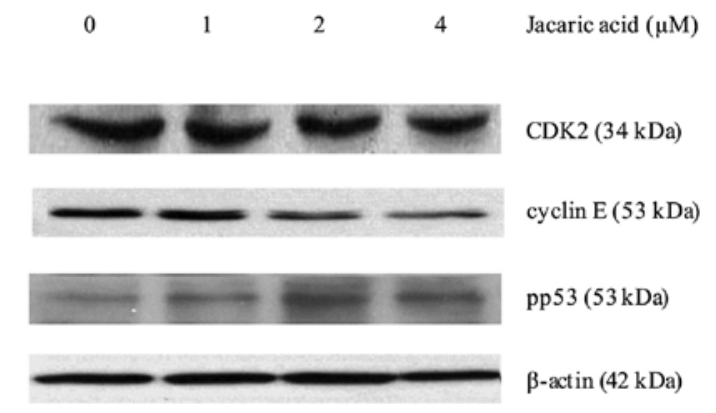

$\mathrm{E}$

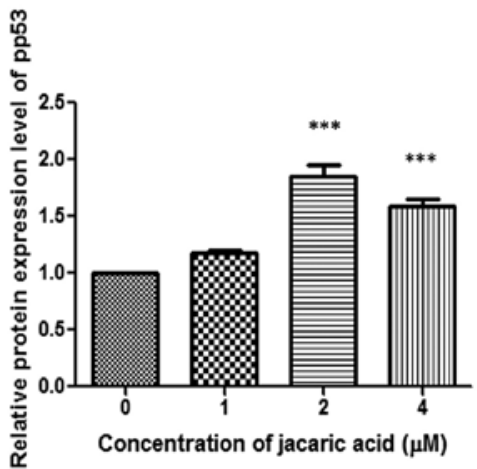

Figure 3. Effects of jacaric acid on the cell cycle profile and the expression of cell cycle-regulatory proteins in EoL-1 cells. (A) EoL-1 cells were incubated with different concentrations of jacaric acid at $37^{\circ} \mathrm{C}$ for $72 \mathrm{~h}$. Cells treated with ethanol acted as the control. The DNA content was analyzed by PI staining and flow cytometry. Cell cycle distribution of the samples was calculated by the Modfit LT 3.0 programme. The results are expressed as mean \pm SE. ${ }^{* * *} \mathrm{P}<0.001$. (B) EoL-1 cells were incubated with 1,2, and $4 \mu \mathrm{M}$ jacaric acid (lanes 2, 3 and 4 , respectively) at $37^{\circ} \mathrm{C}$ for $72 \mathrm{~h}$. Cells treated with ethanol (lane 1) acted as the control. Protein expression levels of CDK2, cyclin E and pp53 were assayed by western blotting with $\beta$-actin protein as an internal control. (C-E) The relative protein expression levels of $\mathrm{CDK} 2$, cyclin $\mathrm{E}$ and pp53 compared to $\beta$-actin were quantified. Results represent mean values $\pm \mathrm{SE}$. ${ }^{* *} \mathrm{P}<0.01{ }^{*}{ }^{* * *} \mathrm{P}<0.001$.

Notably, jacaric acid exhibited no direct cytotoxicity on normal primary myeloid cells such as murine peritoneal macrophages, as the percentage of cell viability of the macrophages remained $>90 \%$ even when the cells were incubated with $100 \mu \mathrm{M}$ jacaric acid for $48 \mathrm{~h}$ (data not shown).

Jacaric acid triggers cell cycle arrest at the $G_{0} / G_{I}$ phase and modulates the expression of cell cycle-regulatory proteins in EoL-1 cells. To determine the possible mechanisms of the anti-proliferative effect of jacaric acid on EoL-1 cells, cells were stained with propidium iodide after incubation with jacaric acid for $72 \mathrm{~h}$, and the cell cycle profile was analyzed by flow cytometry. As shown in Fig. 3A, jacaric acid triggered cell cycle arrest at the $\mathrm{G}_{0} / \mathrm{G}_{1}$ phase, accompanied by a decrease in the percentage of cells at the $S$ phase. To further elucidate the underlying mechanisms, western blotting was carried out in order to examine the protein expression levels of cyclin E, CDK2 and pp53 (Fig. 3B), which are known to be involved in the transition of $G_{0} / G_{1}$ to $S$ phase $(19,20)$. Our results showed that the protein expression levels of cyclin $\mathrm{E}$ and CDK2 decreased in the jacaric acid-treated EoL-1 cells, whereas there was an increase in the expression level of the pp53 protein (Fig. 3C-E). Collectively, the results indicate that jacaric acid treatment of EoL-1 cells leads to cell cycle arrest at the $\mathrm{G}_{0} / \mathrm{G}_{1}$ phase, and modulates the expression of certain cell cycle-regulatory proteins such as cyclin E, CDK2 and pp53.

Jacaric acid induces apoptosis of EoL-1 cells as revealed by the Cell Death Detection ELISA ${ }^{\text {PLUS }}$ kit, Annexin V assay and $J C-1$ dye staining. Apart from triggering cell cycle arrest, another possible mechanism for the growth-inhibitory effect of jacaric acid is the induction of apoptosis. To examine whether jacaric acid induces apoptosis in the EoL-1 cells, the Cell Death Detection ELISA ${ }^{\text {PLUS }}$ kit was used according to the manufacturer's instructions. It was found that jacaric acid induced DNA fragmentation in the EoL-1 cells, as revealed by the increase in the enrichment factor in the jacaric acidtreated EoL-1 cells in a time- and concentration-dependent manner (Fig. 4A), suggesting that jacaric acid induced apoptosis in the EoL-1 cells. To gain further insight into the molecular mechanism underlying the induction of apoptosis, the effects of jacaric acid on altering the expression levels of different apoptosis-regulatory proteins were examined by western blot analysis (Fig. 4B). The expression level of the anti-apoptotic protein Bcl-2 was decreased whereas the expression levels of Bax and caspase-3 proteins were increased (Fig. 4C-E). Apart from the Cell Death Detection ELISA, the Annexin V assay was used to detect the externalization of phosphatidylserine (PS) which is a hallmark of early apoptosis (21). In addition, JC-1 
A

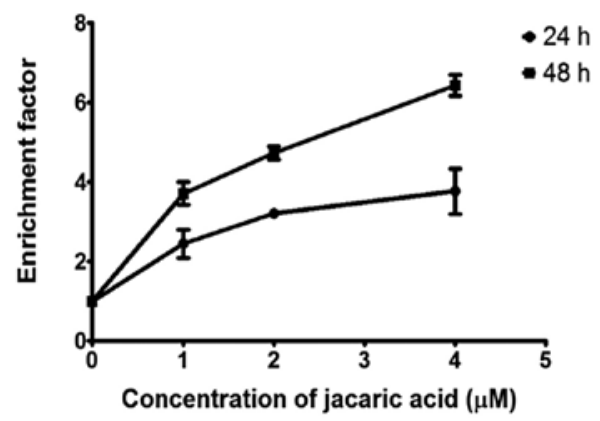

B

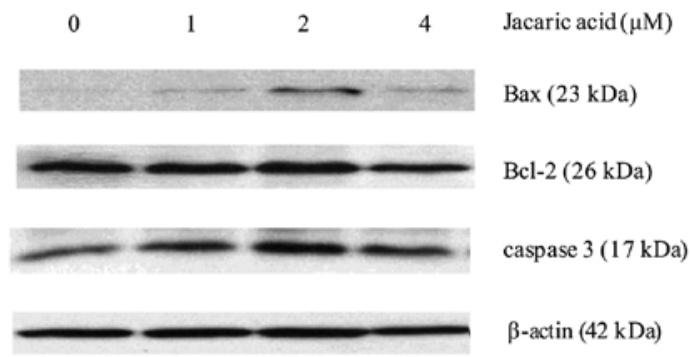

C

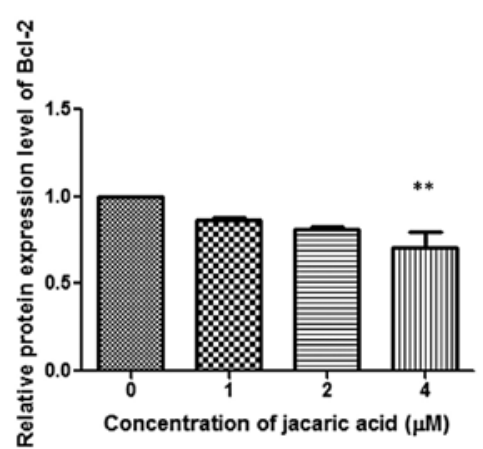

D

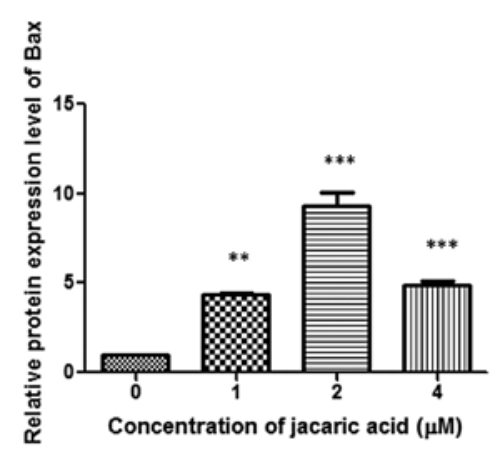

E

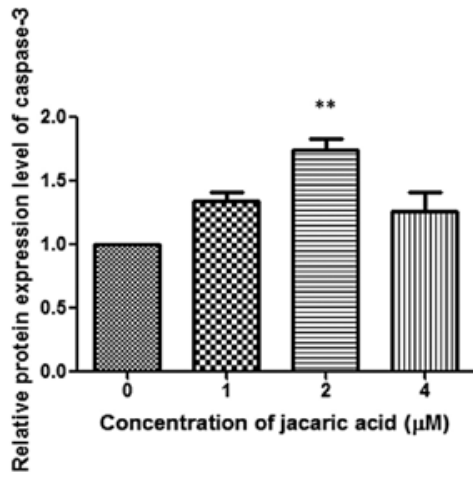

Figure 4. Effects of jacaric acid on the induction of DNA fragmentation and the expression of apoptosis-regulatory proteins in EoL-1 cells. (A) EoL-1 cells were incubated with different concentrations of jacaric acid at $37^{\circ} \mathrm{C}$ for $48 \mathrm{~h}$. Cells treated with ethanol acted as the control. DNA fragments were detected using the Cell Death Detection ELISA ${ }^{\text {PLUS }}$ kit. The extent of apoptosis in the samples was expressed as an increase in the enrichment factor. (B) EoL-1 cells were incubated with 1, 2 and $4 \mu \mathrm{M}$ jacaric acid (lanes 2, 3 and 4, respectively), at $37^{\circ} \mathrm{C}$ for $72 \mathrm{~h}$. Cells treated with ethanol (lane 1 ) acted as the control. Protein expression levels of Bcl-2, Bax and caspase- 3 were assayed by western blotting with $\beta$-actin protein as an internal control. (C-E) The relative protein expression levels of Bcl-2, Bax and caspase-3 compared to $\beta$-actin were quantified. Results represent mean values $\pm \mathrm{SE}$. ${ }^{* *} \mathrm{P}<0.01 ;{ }^{* * * *} \mathrm{P}<0.001$.

dye staining was used to measure the mitochondrial membrane potential which is known to decrease prior to PS externalization and DNA fragmentation $(22,23)$. Our results showed that jacaric acid induced PS externalization in the EoL-1 cells at $24 \mathrm{~h}$ of incubation in a concentration-dependent manner as demonstrated by the Annexin V assay (Fig. 5), and reduced the mitochondrial membrane potential of the EoL-1 cells after staining with JC-1 dye (Fig. 6). Together these results suggest that jacaric acid inhibits the growth of EoL-1 cells by inducing apoptosis.

Jacaric acid induces morphological differentiation of EoL-1 cells and increases the expression of mature eosinophil markers EPO and MBP. Induction of cellular differentiation can also lead to suppression of cell growth (24). As shown in Fig. 7B-D, after treatment with different concentrations of jacaric acid for 9 days, there were more refractive vacuoles in the treated-EoL-1 cells than those in the control (Fig. 7A). This suggests that the granule matrix was altered leading to the presence of small refractive vacuoles when observed under a light microscope. In order to confirm the induction of eosinophilic differentiation of EoL-1 cells by jacaric acid, the expression levels of two eosinophil-specific proteins, eosinophil peroxidase (EPO) and the major basic protein (MBP), were measured by flow cytometry. As shown in Fig. 7E and F, a significant increase in the expression levels of EPO and MBP proteins was noted after 9 days of treatment with $2 \mu \mathrm{M}$ jacaric acid. Collectively, our results indicate that prolonged exposure (9 days) of EoL-1 cells to a low concentration (1-2 $\mu \mathrm{M})$ of jacaric acid induces eosinophilic differentiation of the cells as represented by morphological changes and an elevation in EPO and MBP proteins.

\section{Discussion}

Clonally derived human leukemia cell lines are important research tools for the study of cell transformation, hematopoietic cell differentiation and apoptosis $(25,26)$. The EoL-1 cell line is a well-established human chronic eosinophilic leukemia cell line which has been commonly used as an in vitro model for the study of human eosinophil functions and their regulation, and is particularly useful for analyzing leukemic cell differentiation $(27,28)$. In the present study, we found that jacaric acid, one of the CLNA isomers, inhibited the growth of EoL-1 cells in a time- and concentration-dependent manner, as measured by MTT reduction colorimetric assay and the CyQuant ${ }^{\circledR}$ NF Cell Proliferation fluorometric assay. This is similar to a previous report which demonstrated that CLNA produced by alkali isomerization of $\alpha$-linolenic acid displayed a potent antitumor effect on a wide range of human 
A

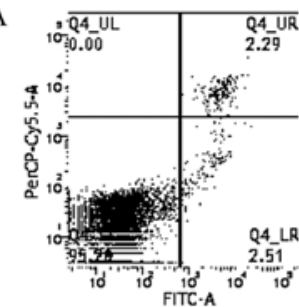

B

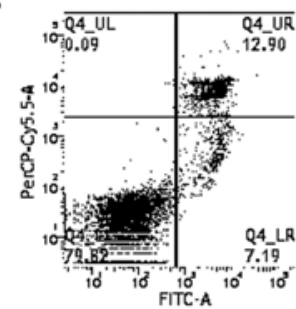

$\mathrm{C}$

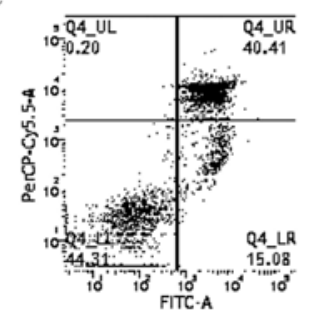

D

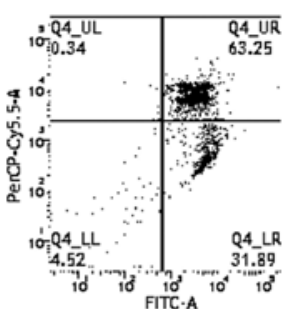

E
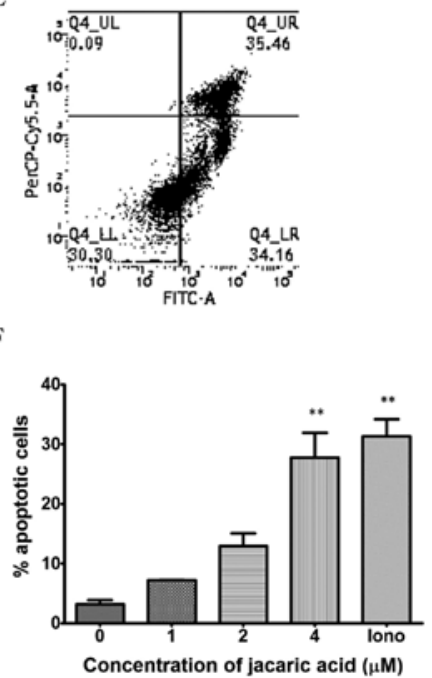

A

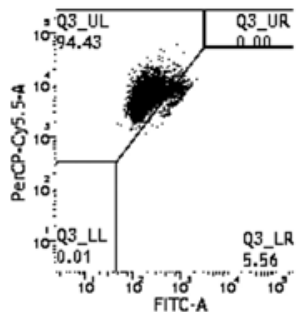

B

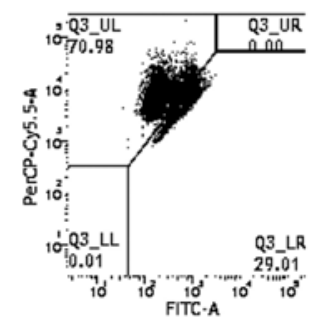

$\mathrm{C}$

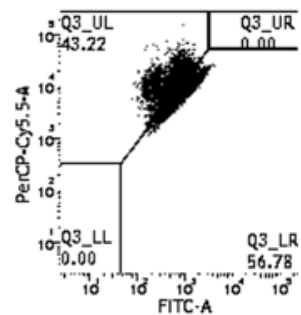

D

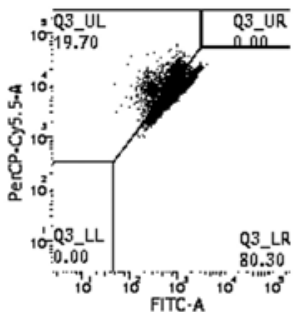

E

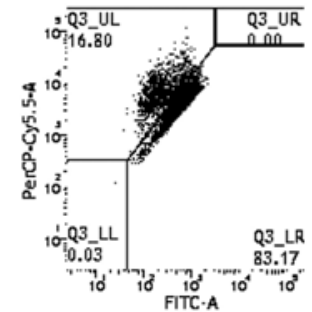

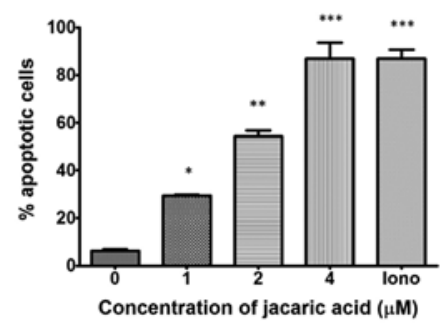

Figure 5. Jacaric acid induces phosphatidylserine externalization in EoL-1 cells. EoL-1 cells were incubated with either (A) ethanol control, or (B) $1 \mu \mathrm{M}$ jacaric acid, (C) $2 \mu \mathrm{M}$ jacaric acid, (D) $4 \mu \mathrm{M}$ jacaric acid and (E) $200 \mathrm{nM}$ calcium ionophore as a positive control at $37^{\circ} \mathrm{C}$ for $24 \mathrm{~h}$. After incubation, the cells were stained with Annexin V-GFP fusion protein and PI. The fluorescence intensity was measured by the FACSCanto flow cytometer. (F) The results were quantified and are expressed as mean values $\pm \mathrm{SE}$. ${ }^{* *} \mathrm{P}<0.01$.

cancer cell lines in vitro (12). Our results indicate that among the four CLNA isomers tested, jacaric acid exhibited the most potent antitumor effect on EoL-1 cells and this is in line with the finding of Shinohara et al (29) who showed that jacaric acid also exerted the most potent in vitro cytotoxic effect on human adenocarcinoma DLD-1 cells. To investigate whether jacaric acid inhibits the growth of EoL-1 cells through triggering cell cycle arrest, the cells were stained with PI, and the cell cycle profile was analyzed by flow cytometry. Our results showed that jacaric acid triggered cell cycle arrest at the $\mathrm{G}_{0} /$ $\mathrm{G}_{1}$ phase, accompanied by a decrease in the percentage of cells at the $\mathrm{S}$ phase. Cell cycle progression is known to be regulated by different cyclins and cyclin-dependent kinases (CDK) (30). Some studies have shown that cell cycle arrest at the $\mathrm{G}_{0} / \mathrm{G}_{1}$ phase is regulated by CDK2, CDK4 and cyclin $\mathrm{E}(30-32)$. Other studies have demonstrated that an increase in the protein expression levels of the p21, p27 and p53 proteins caused cell cycle arrest at the $G_{0} / G_{1}$ phase in human breast carcinoma and human lung cancer A549 cells $(32,33)$. Our present study showed that the protein expression levels of cyclin $\mathrm{E}$ and CDK2 were decreased in the jacaric acid-treated EoL-1 cells, whereas there was an increase in the expression level of the pp53 protein. Taken together, our results demonstrated that jacaric acid led to cell cycle arrest at the $\mathrm{G}_{0} / \mathrm{G}_{1}$ phase, which was accompanied by alteration of the cell cycle-regulatory proteins controlling the $\mathrm{G}_{1}$ phase mitotic checkpoint.

Figure 6. Jacaric acid induces mitochondrial membrane depolarization in EoL-1 cells. EoL-1 cells were incubated with either (A) ethanol control, or (B) $1 \mu \mathrm{M}$ jacaric acid, (C) $2 \mu \mathrm{M}$ jacaric acid, (D) $4 \mu \mathrm{M}$ jacaric acid and (E) $200 \mathrm{nM}$ calcium ionophore as a positive control at $37^{\circ} \mathrm{C}$ for $24 \mathrm{~h}$. After incubation, the cells were stained with JC-1 dye. The fluorescence intensity was measured by the FACSCanto flow cytometer. (F) The results were quantified and are expressed as mean values $\pm \mathrm{SE}$. ${ }^{*} \mathrm{P}<0.05 ;{ }^{* *} \mathrm{P}<0.01 ;{ }^{* * *} \mathrm{P}<0.001$.

Induction of apoptosis is another mechanism which may account for the observed anti-proliferative effect of jacaric acid on EoL-1 cells. Previous studies have demonstrated that $\alpha$-eleostearic acid, another isomer of CLNA, induced DNA fragmentation, increased caspase activity and expression of caspase mRNA in human colon cancer DLD-1 cells and these were shown to be associated with lipid peroxidation (13). A recent report showed that jacaric acid could induce apoptosis in human prostate cancer cells (34). Using the Cell Death Detection ELISA ${ }^{\text {PLUS }}$ kit, we found that there was an increase in DNA fragmentation in the jacaric acidtreated EoL-1 cells, suggesting the occurrence of apoptosis in the EoL-1 cells. Western blotting indicated that the expression level of the anti-apoptotic Bcl-2 protein was decreased. On the other hand, the expression levels of several proteins that are involved in the apoptotic pathway, including Bax and caspase-3, were increased, and these results are in line with previous findings (35). In addition, an elevation in PS externalization and increased mitochondrial membrane depolarization in the jacaric acid-treated EoL-1 cells further supported our finding that jacaric acid induces apoptosis in EoL-1 cells.

It has been reported that EoL-1 cells can be induced to differentiate into mature, eosinophilic granule-containing cells in response to a number of stimuli, including cytokines 
A

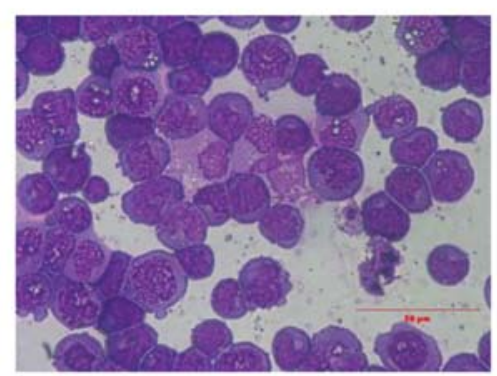

C

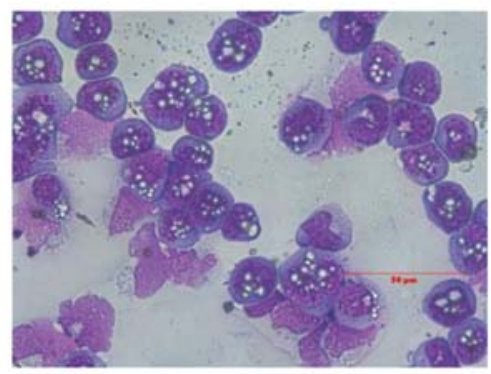

$\mathrm{E}$

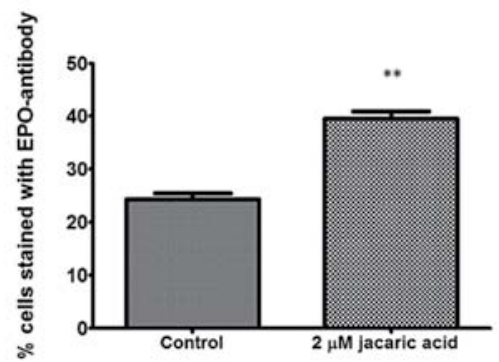

B

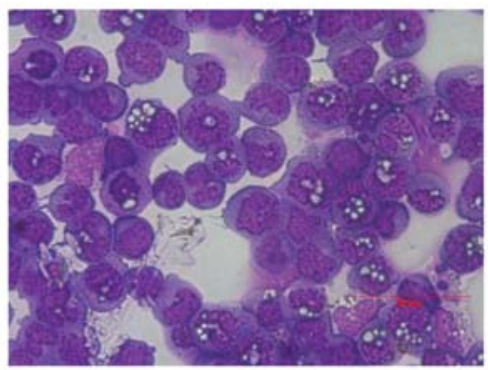

D

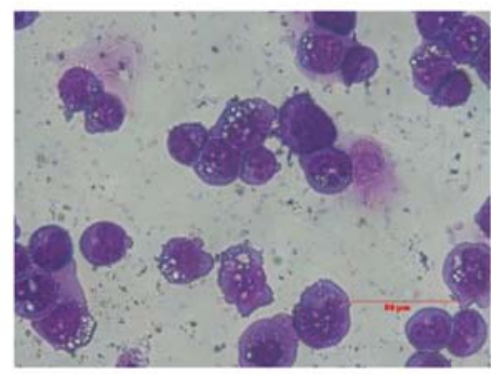

$\mathrm{F}$

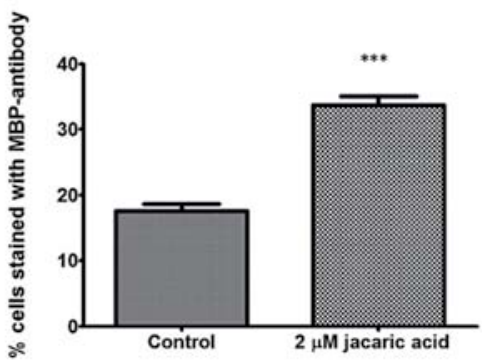

Figure 7. Effects of jacaric acid on the morphological differentiation and changes in the expression of intracellular EPO and MBP in EoL-1 cells. EoL-1 cells were treated with either (A) ethanol control,(B) $0.5 \mu \mathrm{M}$ jacaric acid, (C) $1 \mu \mathrm{M}$ jacaric acid or (D) $2 \mu \mathrm{M}$ jacaric acid at $37^{\circ} \mathrm{C}$ for 9 days. Afterwards, the cells were cytocentrifuged onto microscopic slides and stained with Hemacolor staining solution (magnification, $\mathrm{x} 400$ ). EoL-1 cells treated with either ethanol control or $2 \mu \mathrm{M}$ jacaric acid at $37^{\circ} \mathrm{C}$ for 9 days were incubated with either mouse IgG isotype, mouse anti-human EPO or MBP monoclonal antibody. The expression of EPO and MBP was determined by enhanced fluorescence following incubation with the mouse anti-human monoclonal antibody compared with cells incubated with mouse IgG isotype. The results are expressed as the mean percentage of cells stained with $(\mathrm{E}) \mathrm{EPO}$ or $(\mathrm{F}) \mathrm{MBP}$ antibody $\pm \mathrm{SE}$. ${ }^{* *} \mathrm{P}<0.01 ;{ }^{* * *} \mathrm{P}<0.001$.

such as granulocyte-colony stimulating factor and tumor necrosis factor- $\alpha$ (36), chemokines such as leukotactin (28), and small molecules such as butyrate (37), dibutyryl cyclic AMP, prostaglandin E2 and forskolin (38). In addition, previous research from our laboratory demonstrated that the green tea catechin epigallocatechin-3-gallate (18) inhibited the growth of EoL-1 cells in vitro by inducing cellular differentiation. To the best of our knowledge, the ability of CLNA to induce differentiation in human myeloid leukemia cells has not yet been reported. In the present study, EoL-1 cells treated with a lower concentration (1-2 $\mu \mathrm{M})$ of jacaric acid for a longer period of time ( 9 days) had more refractive vacuoles in their cytoplasm than those in the control, suggesting that EoL-1 cells could be triggered to undergo morphological differentiation into mature eosinophil-like cells. Moreover, jacaric acid also upregulated the expression levels of two eosinophil-specific granule proteins, EPO and $\mathrm{MBP}$, in the EoL-1 cells under the prescribed experimental conditions. The results, when taken together, suggest that jacaric acid can exhibit anti-proliferative activity on human eosinophilic EoL-1 cells by triggering cell cycle arrest at the $G_{0} / G_{1}$ phase, by inducing leukemic cell apoptosis, and by inducing eosinophilic differentiation of leukemia cells. Since a recent report showed that jacaric acid did not exhibit any significant toxicity in vivo (39), further elucidation of the anti-leukemic efficacy and action mechanisms of jacaric acid in vivo may provide a better insight into the development of jacaric acid as a potential candidate for the treatment of certain forms of myeloid leukemia with minimal toxicity and few side effects.

\section{Acknowledgements}

We thank Miss Ada Kong for the excellent technical assistance for this reserach.

\section{References}

1. Jude CD, Gaudet JJ, Speck NA and Ernst P: Leukemia and hematopoietic stem cells: balancing proliferation and quiescence. Cell Cycle 7: 586-591, 2008. 
2. Leung KN, Mak NK and Fung MC: Cytokines in the differentiation therapy of leukemia: from laboratory investigations to clinical applications. Crit Rev Clin Lab Sci 42: 473-514, 2005.

3. Tsiftsoglou AS, Pappas IS and Vizirianakis IS: Mechanisms involved in the induced differentiation of leukemia cells. Pharmacol Ther 100: 257-290, 2003.

4. Nagao K and Yanagita T: Conjugated fatty acids in food and their health benefits. Biosci Bioeng 100: 152-157, 2005

5. Griinari JM, Corl BA, Lacy SH, Chouinard PY, Nurmela KV and Bauman DE: Conjugated linoleic acid is synthesized endogenously in lactating dairy cows by Delta(9)-desaturase. J Nutr 130: 2285-2291, 2000.

6. Takagi T and Itabashi Y: Occurrence of mixtures of geometricalisomers of conjugated octadecatrienoic acids in some seed oils: Analysis by open-tubular gas liquid chromatography and high performance liquid chromatography. Lipids 16: 546-551, 1981.

7. Bhaskar N, Kinami T, Miyashita K, Park SB, Endo Y and Fujimoto K: Occurrence of conjugated polyenoic fatty acids in seaweeds from the Indian Ocean. Z Naturforsch C 59: 310-314, 2004.

8. Dilzer A and Park Y: Implication of conjugated linoleic acid (CLA) in human health. Crit Rev Food Sci Nutr 52: 488-513, 2012.

9. Tanaka T, Hosokawa M, Yasui Y, Ishigamori R and Miyashita K: Cancer chemopreventive ability of conjugated linolenic acids. Int J Mol Sci 12: 7495-7509, 2011.

10. Koba K, Akahoshi A, Yamasaki M, et al: Dietary conjugated linolenic acid in relation to CLA differently modifies body fat mass and serum and liver lipid levels in rats. Lipids 37: 343-350, 2002.

11. Hennessy AA, Ross RP, Devery R and Stanton C: The health promoting properties of the conjugated isomers of $\alpha$-linolenic acid. Lipids 46: 105-119, 2011.

12. Igarashi $\mathrm{M}$ and Miyazawa T: Newly recognized cytotoxic effect of conjugated trienoic fatty acids on cultured human tumor cells. Cancer Lett 148: 173-179, 2000.

13. Tsuzuki T, Tokuyama Y, Igarashi $M$ and Miyazawa T: Tumor growth suppression by alpha-eleostearic acid, a linolenic acid isomer with a conjugated triene system, via lipid peroxidation. Carcinogenesis 25: 1417-1425, 2004.

14. Grossmann ME, Mizuno NK, Dammen ML, Schuster T, Ray A and Cleary MP: Eleostearic acid inhibits breast cancer proliferation by means of an oxidation-dependent mechanism. Cancer Prev Res 2: 879-886, 2009.

15. Saito H, Bourinbaiar A, Ginsburg M, et al: Establishment and characterization of a new human eosinophilic leukemia cell line. Blood 66: 1233-1240, 1985.

16. Liao $X$ and Leung KN: Tryptanthrin induces growth inhibition and neuronal differentiation in the human neuroblastoma LA-N-1 cells. Chem Biol Interact 203: 512-521, 2013.

17. Liao XM and Leung KN: Indirubin-3'-oxime induces mitochondrial dysfunction and triggers growth inhibition and cell cycle arrest in human neuroblastoma cells. Oncol Rep 29: 371-379, 2013.

18. Lung HL, Ip WK, Wong CK, Mak NK, Chen ZY and Leung KN: Anti-proliferative and differentiation-inducing activities of the green tea catechin epigallocatechin-3-gallate (EGCG) on the human eosinophilic leukemia EoL-1 cell line. Life Sci 72: 257-268, 2002.

19. Wilken R, Veena MS, Wang MB and Srivatsan ES: Curcumin: A review of anti-cancer properties and therapeutic activity in head and neck squamous cell carcinoma. Mol Cancer 10: 12, 2011.

20. Li L, Dai HJ, Ye M, et al: Lycorine induces cell-cycle arrest in the G0/G1 phase in K562 cells via HDAC inhibition. Cancer Cell Int 12: 49, 2012.

21. Martin SJ, Finucane DM, Amarante-Mendes GP, O'Brien GA and Green DR: Phosphatidylserine externalization during CD95-induced apoptosis of cells and cytoplasts requires ICE/CED-3 protease activity. J Biol Chem 271: 28753-28756, 1996.
22. Castedo M, Macho A,Zamzami N, et al: Mitochondrial perturbations define lymphocytes undergoing apoptotic depletion in vivo. Eur J Immunol 25: 3277-3284, 1995.

23. Zamzami N, Marchetti P, Castedo M, et al: Sequential reduction of mitochondrial transmembrane potential and generation of reactive oxygen species in early programmed cell death. J Exp Med 182: 367-377, 1995.

24. Hansen CM, Mathiasen IS and Binderup L: The anti-proliferative and differentiation-inducing effects of vitamin D analogs are not determined by the binding affinity for the vitamin $D$ receptor alone. J Investig Dermatol Symp Proc 1: 44-48, 1996.

25. Drexler HG, Matsuo AY and MacLeod RA: Continuous hematopoietic cell lines as model systems for leukemia-lymphoma research. Leuk Res 24: 881-911, 2000.

26. Mayani H, Flores-Figueroa E and Chavez-Gonzalez A: In vitro biology of human myeloid leukemia. Leuk Res 33: 624-637, 2009.

27. Cools J, Quentmeier H, Huntly BJ, et al: The EOL-1 cell line as an in vitro model for the study of FIP1L1-PDGFRA-positive chronic eosinophilic leukemia. Blood 103: 2802-2805, 2004.

28. Lee JS and Kim IS: Leukotactin-1/CCL15 induces cell migration and differentiation of human eosinophilic leukemia EoL-1 cells through PKCdelta activation. Mol Biol Rep 37: 2149-2156, 2010.

29. Shinohara N, Tsuduki T, Ito J, et al: Jacaric acid, a linolenic acid isomer with a conjugated triene system, has a strong antitumor effect in vitro and in vivo. Biochim Biophys Acta 1821: 980-988, 2012.

30. Nigg EA: Cyclin-dependent protein kinases: key regulators of the eukaryotic cell cycle. Bioessays 17: 471-480, 1995.

31. Geng Y, Whoriskey W, Park MY, et al: Rescue of cyclin D1 deficiency by knockin cyclin E. Cell 97: 767-777, 1999.

32. Liang YC, Lin-Shiau SY, Chen CF and Lin JK: Inhibition of cyclin-dependent kinases 2 and 4 activities as well as induction of Cdk inhibitors p21 and p27 during growth arrest of human breast carcinoma cells by (-)-epigallocatechin-3-gallate. J Cell Biochem 75: 1-12, 1999.

33. Lu HF, Chen YS, Yang JS, et al: Gypenosides induced G0/G1 arrest via inhibition of cyclin $\mathrm{E}$ and induction of apoptosis via activation of caspases-3 and -9 in human lung cancer A-549 cells. In vivo 22: $215-221,2008$

34. Gasmi J and Sanderson JT: Jacaric acid and its octadecatrienoic acid geoisomers induce apoptosis selectively in cancerous human prostate cells: a mechanistic and 3-D structure-activity study. Phytomedicine 20: 734-742, 2013.

35. Sun Y,Lin Y,Li H, Liu J, Sheng X and Zhang W: 2,5-Hexanedione induces human ovarian granulosa cell apoptosis through BCL-2, BAX, and CASPASE-3 signaling pathways. Arch Toxicol 86: 205-215, 2012.

36. Shintaku N, Ohshima Y, Jung EY, et al: Induction of eosinophilic granules, nonspecific esterase activity and CD14 expression in the human eosinophilic leukemia cell line, EOL-1. Hematol Oncol 12: 129-139, 1994.

37. Izumi T, Kishimoto S, Takano T, et al: Expression of human platelet-activating factor receptor gene in EoL-1 cells following butyrate-induced differentiation. Biochem J 305: 829-835, 1995.

38. Tai G, Eun-Young J, Yuji H, et al: Different effects of cyclic AMP and butyrate on eosinophilic differentiation, apoptosis and bcl-2 expression of a human eosinophilic leukemia cell line, EoL-1. Hematol Oncol 14: 181-192, 1996.

39. Shinohara N, Ito J, Tsuduki T, et al: Jacaric acid, a linolenic acid isomer with a conjugated triene system, reduces stearoyl-CoA desaturase expression in liver of mice. J Oleo Sci 61: 433-441, 2012. 